\title{
Keikutsertaan menjadi akseptor KB ditinjau dari aspek sosial budaya dan dukungan keluarga
}

\author{
Nopita Yanti Sitorus*, R. Maimunah
}

Program Studi D-III Kebidanan STIKes Flora. *Email: nopistr27@gmail.com

\section{Abstract \\ Socio-cultural and family aspects among female participation in family planning}

Background: The family planning program is one way to suppress population growth. However, the phenomenon in some communities regarding family planning is that there are values, culture and norms that have not been able to accept birth control programs and think that family planning is not in accordance with the values believed so that the family also does not provide support.

Purpose: To analyze the socio-cultural relationship and family support with family planning participation.

Method: A quantitative study with a cross sectional approach. The research was conducted in the area of public Health Centre (Puskesmas) Kota Datar, Tandem Hulu I Village. The study population was 1711 people and the sample was 324 responden taken by simple random sampling. Data analysis used univariate analysis, bivariate analysis with chi-square test at the $95 \%$ confidence level $(\square=0.05)$.

Results: The socio-culture and family support were related to family planning participation in the working area of the Public Health Centre (Puskesmas) Kota Datar, Tandem Hulu I Village, Hamparan Perak District, Deli Serdang Regency, $\mathrm{p}<0.05$.

Conclusion: The wife who do not get support socio-culture and get support from family tend to use contraceptives and wifes who has support socio-culture and do not get support from their husbands tend not to use contraceptives.

\section{Keywords: Socio-culture; Family support; Participation; Female; Family planning}

Pendahuluan : Program KB merupakan salah satu cara untuk menekan pertumbuhan penduduk. Namun, fenomena pada sebagian masyarakat tentang KB yaitu adanya nilai, budaya dan norma yang belum dapat menerima program pengaturan kelahiran dan menganggap KB tidak sesuai dengan nilai-nilai yang diyakini sehingga keluarga juga tidak memberikan dukungan

Tujuan: Untuk menganalisis hubungan sosial budaya dan dukungan keluarga dengan keikutsertaan KB.

Metode : Penelitian kuantitatif dengan pendekatan cross sectional. Penelitian dilakukan di wilayah Kerja Puskesmas Kota Datar yaitu di Desa Tandem Hulu I Kecamatan Hamparan Perak Kabupaten Deli Serdang. Populasi penelitian sebanyak 1.711 orang dan sampel diperoleh sebanyak 324 responden. Penarikan sampel secara acak sederhana (simple random sampling). Analisis data menggunakan analisis univariat, analisis bivariat dengan uji chi-square pada tingkat kepercayaan $95 \%(p<0,05)$.

Hasil: Menunjukkan bahwa sosial budaya dan dukungan keluarga berhubungan dengan keikutsertaan KB di Wilayah kerja Puskesmas Kota Datar Desa Tandem Hulu I Kecamatan Hamparan Perak Kabupaten Deli Serdang, $p<0,05$.

Simpulan : Ibu yang tidak mendapat dukungan sosial budaya dan mendapatkan dukungan dari keluarga cenderung menggunakan alat kontrasepsi, dan ibu yang mendapat dukungan sosial budaya dan tidak mendapatkan dukungan suami cenderung tidak menggunakan alat kontrasepsi.

\section{Kata Kunci : Sosial budaya; Dukungan keluarga; Sosial-budaya; Keikutsertaan KB}

\section{PENDAHULUAN}

Jumlah penduduk di Indonesia terus mengalami peningkatan dari tahun 2012 sebanyak 245,43 juta jiwa sedangkan tahun 2016 sebanyak
258,70 jiwa, sedangkan laju pertumbuhan penduduk mengalami penurunan dari tahun 2012 sebesar 1,41\% dan tahun 2016 sebesar 1,26\% (BKKBN, 2017). Berdasarkan hasil Survei 
Penduduk Antar Sensus (SUPAS) 2015 jumlah penduduk Indonesia pada 2020 diperkirakan sebanyak 269,6 juta jiwa. Di mana jumlah penduduk laki-laki 135,34 juta jiwa, lebih banyak dibanding perempuan yang hanya 134,27 juta jiwa (BPS, 2018).

Salah satu cara untuk menekan jumlah penduduk yaitu dengan cara meningkatkan pelayanan Keluarga Berencana. Program Keluarga Berencana bertujuan untuk menciptakan kesejahteraan ekonomi, spritual dan sosial budaya, pendidikan agar dapat tercipta keseimbangan yang baik dengan kemampuan produksi nasional (Manuaba, 2014).

Menurut data dari BKKBN tahun 2005 bila angka keikutsertaan KB tetap sama sebesar $60,3 \%$, maka jumlah penduduk Indonesia tahun 2015 diperkirakan mencapai 255,5 juta jiwa. Bila keikutsertaan ber KB turun 0,5\% per tahun, maka jumlah penduduk Indonesia pada tahun 2015 meningkat menjadi 264,4 juta jiwa sehingga jumlah penduduk Indonesia akan semakin padat, sebaliknya jika keikutsertaan KB dinaikkan 1\% per tahun, diperkirakan jumlah penduduk Indonesia pada tahun 2015 sekitar 237,8 juta jiwa (BKKBN, 2017).

Program KB di Indonesia termasuk yang dianggap berhasil di tingkat internasional. Hal ini terlihat dari kontribusinya terhadap penurunan pertumbuhan penduduk, sebagai akibat dari penurunan angka kesuburan total (Total Fertility Rate, TFR). Menurut Survey Demografi Kesehatan Indonesia (SDKI), TFR pada kurun waktu 19671970 menurun dari 5,6 menjadi hampir setengahnya dalam 30 tahun, yaitu 2,4 pada tahun 2016. Demikian juga pencapaian cakupan pelayanan KB (Contraceptive Prevalence Rate, $\mathrm{CPR}$ ) dengan berbagai metode meningkat menjadi 60,3\% pada tahun 2016 (Badan Pusat Statistik, 2016).

Data SUSENAS (Survey Sosial Ekonomi Nasional) tahun 2015 menunjukkan persentase PUS (Pasangan Usia Subur) yang sedang menggunakan alat/cara KB sebesar 59,98 persen, pernah menggunakan tetapi sekarang tidak menggunakan sebesar 12,64 persen, dan PUS yang tidak menggunakan KB sebesar 27,38 persen. Berdasarkan tipe daerah, PUS di perdesaan yang menggunakan alat/cara KB untuk menunda/mencegah kehamilan relatif lebih tinggi dibandingkan dengan di perkotaan (61,92 persen berbanding 57,98 persen). (Badan Pusat Statistik, 2015).

Fenomena yang ada di masyarakat yang menyangkut adanya nilai dan norma di masyarakat yang belum dapat menerima program pengaturan kelahiran dan menganggap hal tersebut tidak sesuai dengan nilai-nilai yang diyakini masyarakat (Noorkasiani, Heryati, \& Ismail, 2016). Masyarakat masih mempercayai bahwa banyak anak banyak rejeki, tiap anak membawa rejeki sendiri-sendiri dan anak sebagai tempat bergantung di hari tua. Sehingga slogan dua anak lebih baik masih sulit diterima oleh masyarakat ( Darmawati, \& Rakhmah, 2017).

Desa Tandem Hulu I Kabupaten Deli Serdang merupakan salah satu daerah dengan kultur masyarakat yang masih memegang erat nilai-nilai sosial budaya. Dalam hal ini kultur yang utama di kalangan masyarakat bahwa perempuan harus tunduk kepada suami, rasa malu berhubungan dengan orang lain dalam hal memasang alat kontrasepsi, masih ada anggapan banyak anak banyak rezeki. Nilai dan norma sosial yang ada di masyarakat sedikit banyak akan mempengaruhi persepsi pasangan usia subur terhadap program KB. Permasalahan utama yang dihadapi dalam pelaksanaan program KB pada umumnya kultur masyarakat yang masih memegang erat faktor sosial dan budaya (Nurmaliah, 2011). Berdasarkan hasil studi yang dilakukan peneliti pada tanggal 2 Maret 2020 di Wilayah Kerja Puskesmas Kota Datar jumlah pasangan usia subur yaitu 1.888 orang dimana akseptor KB aktif berjumlah 1.103 orang $(58,42 \%)$, sehingga masih ada 785 orang $(41,57 \%)$ yang tidak mengikuti program KB. Dari hasil wawancara dengan 12 orang ibu yang tidak mengikuti KB, disebabkan oleh berbagai alasan diantaranya karena faktor sosial dan budaya seperti 4 ibu berpendapat bahwa semakin banyak anak maka semakin bertambah rejeki, 3 ibu tidak diizinkan suami dan keluarga besar, 2 ibu tidak sesuai dengan nilai keyakinan keluarga, 3 ibu takut terhadap efek samping dari penggunaan kontrasepsi.

\section{METODOLOGI PENELITIAN}

Penelitian survei analitik dengan rancangan penelitian cross sectional. Lokasi penelitian di wilayah kerja Puskesmas Kota Datar yaitu di Desa Tandem Hulu I Kecamatan Hamparan Perak Kabupaten Deli Serdang. Penelitian dilakukan sejak bulan Januari sampai dengan bulan Juli 
2020, mendapatkan surat layak etik dengan nomor : 216.05/UI/2020 dari Fakultas Kedokteran Universitas Sumatera Utara. Populasinya semua wanita dari pasangan Usia Subur yang menggunakan alat kontrasepsi yang bertempat tinggal di Desa Tandem Hulu I Kecamatan Hamparan Perak Kabupaten Deli Serdang sebanyak 1.711 orang dan sampelnya sebanyak 324 responden yang diambil secara acak sederhana (simple random sampling).

Pengumpulan data menggunakan kuesioner yang terdiri dari data karakteristik pasangan usia subur berupa : umur, pendidikan, pekerjaan, jumlah anak. Selain itu juga terdapat kuesioner aspek social budaya dan dukungan keluarga masing - masing variable sebanyak 10 item pertanyaan. Analisis Univariat untuk melihat frekuensi dan distribusi. Analisis yang dilakukan untuk mengetahui adanya hubungan antara variable independen dengan variable dependen dengan menggunakan Chi-Square dengan tingkat kepercayaan $95 \%(p<0,05)$. Variabel social budaya dengan alat ukur menggunakan kuesioner sebanyak 10 pertanyaan, hasil ukurnya mendukung dan tidak mendukung dengan skala ukur ordinal. Variabel dukungan keluarga menggunakan alat ukur kuesioner sebanyak 10 pertanyaan, hasil ukurnya mendukung dan tidak mendukung dengan skala ukur ordinal

HASIL

Tabel 1. Karakteristik Demografi Responden N=324

$\begin{array}{lllll}\text { Demografi } & \mathrm{n} & \% & M \pm S D\end{array}$

\begin{tabular}{llccc}
\hline $\begin{array}{l}\text { Usia Ibu (Tahun)(Rentang: 20-46) } \\
\text { Jumlah Anak Yang Dimiliki } \\
\text { (Rentang: 1-5) }\end{array}$ & & 324 & & $30.53 \pm 7.494$ \\
& & 324 & & $2.20 \pm 0.908$ \\
Keikutsertaan KB & Ikut & & & \\
& Tidak ikut & 236 & 72.8 & \\
Jenis Kontrasepsi & Pil & 98 & 27.2 \\
& Suntik & 81 & 38,1 \\
& IUD/AKDR & 47 & 19,9 \\
& Implant & 18 & 7,6 \\
Pendidikan Ibu & & & \\
& SD & 22 & 6,8 \\
& SMP & 130 & 40,1 \\
& SMA & 154 & 47,5 \\
& D3/S1 & 18 & 5,6 \\
Pekerjaan Ibu & & & & \\
& Bekerja & 104 & 32,1 \\
& Tidak Bekerja & 220 & 67.9
\end{tabular}

Berdasarkan tabel 1. diketahui bahwa responden berusia antara 20 tahun sampai 46 tahun dengan mean sebesar 30.53 dan standar deviasi 7.494. Jumlah anak yang dimiliki responden dengan rentang 1 orang sampai 5 orang dengan mean 2.20 dan standar deviasi 0.908 . Responden yang ikutserta menggunakan KB sebanyak 236 orang $(72.8 \%)$ sedangkan yang tidak ikutserta menggunakan KB sebanyak 88 orang $(27.2 \%)$. Sebagian besar responden menggunakan KB jenis pil sebanyak 90 orang (38.1\%), sebagian kecil responden menggunakan $\mathrm{KB}$ jenis implant sebanyak 18 orang (5.6\%).Berdasarkan pendidikan terakhir ibu, bahwa sebagian besar responden berpendidikan SMA sebanyak 154 orang (47.5\%), sebagian kecil berpendidikan D3/S1 
sebanyak 18 orang (5.6\%). Berdasarkan pekerjaan, bahwa sebagian besar responden tidak bekerja sebanyak 220 orang $(67,9 \%)$.

Tabel 2. Variabel Yang Bergaruh Terhadap Keikutsertaan Menjadi Akseptor KB ( $N=324)$

\begin{tabular}{|c|c|c|c|c|c|c|c|}
\hline \multirow{3}{*}{ Variabel } & \multicolumn{4}{|c|}{ Keikutsertaan KB } & \multirow{2}{*}{\multicolumn{2}{|c|}{ Jumlah }} & \multirow{3}{*}{$p$-value } \\
\hline & \multicolumn{2}{|c|}{ Ikutserta } & \multicolumn{2}{|c|}{$\begin{array}{c}\text { Tidak lkut } \\
\text { serta }\end{array}$} & & & \\
\hline & $\mathrm{n}$ & $\%$ & $\mathrm{n}$ & $\%$ & $\mathbf{N}$ & $\%$ & \\
\hline \multicolumn{8}{|l|}{ Sosial Budaya } \\
\hline Mendukung & 38 & 16,1 & 76 & 86,4 & 114 & 35,2 & \\
\hline Tidak mendukung & 198 & 83,9 & 12 & 13,6 & 210 & 64,8 & 0,000 \\
\hline \multicolumn{8}{|c|}{ Dukungan Keluarga } \\
\hline Mendukung & 201 & 85,2 & 19 & 21,6 & 220 & 67,9 & 0000 \\
\hline Tidak mendukung & 35 & 14,8 & 69 & 78,4 & 104 & 32,1 & 0,000 \\
\hline
\end{tabular}

Berdasarkan tabel 2. diketahui bahwa dari 114 responden yang mendukung sosial budaya yang ada selama ini mayoritas tidak ikutserta menggunakan alat kontrasepsi KB sebanyak 76 orang $(86.4 \%)$, dari 210 responden yang menyatakan sosial budaya tidak mendukung mayoritas ikut serta menggunakan alat kontrasepsi KB sebanyak 198 orang (83.9\%). Hasil uji statistik pada analisis bivariat menggunakan Chi-Square diperoleh $p$-value sebesar $0,000<0,05$ artinya ada hubungan yang signifikan antara sosial budaya dengan keikutsertaan KB. Dari 220 responden yang menyatakan keluarganya mendukung mayoritas ikut sertaan menggunakan KB sebanyak 201 orang $(85.2 \%)$, dari 104 responden yang menyatakan keluarganya tidak mendukung mayoritas tidak ikutserta menggunakan KB sebanyak 69 orang (78.4\%). Hasil uji statistik pada analisis bivariat menggunakan Chi-Square diperoleh $p$-value sebesar $0,000<0,05$ artinya ada hubungan yang signifikan antara dukungan keluarga dengan keikutsertaan KB

\section{PEMBAHASAN}

Berdasarkan hasil penelitian menunjukkan bahwa ada hubungan yang signifikan antara sosial budaya dengan keikutsertaan KB di Wilayah kerja Puskesmas Kota Datar Desa Tandem Hulu I Kecamatan Hamparan Perak Kabupaten Deli Serdang, $p=0,000<0,05$. Responden yang mendukung sosial budaya mayoritas ikutserta menggunakan alat kontrasepsi KB, sedangkan yang tidak ikutserta. Responden yang menyatakan sosial budaya tidak mendukung mayoritas ikutserta menggunakan KB, sedangkan yang tidak ikutserta. Sejalan dengan penelitian yang dilakukan Assalis (2015) di Wilayah Kerja Puskesmas Branti Natar Lampung Selatan tahun 2015 mendapatkan hasil bahwa ada hubungan sosial budaya dengan pemilihan metode kontrasepsi.

Penelitian yang dilakukan oleh Setiowati (2018) di Puskesmas Wilayah Kecamatan Cimahi Selatan Kota Cimahi didapatkan hasil terdapat hubungan yang signifikan antara faktor budaya terhadap penggunaan Alat Kontrasepsi Dalam Rahim. Kelompok kasus sebagian besar responden menyatakan bahwa faktor budaya tidak mendukung penggunaan Alat Kontrasepsi Dalam Rahim, sedangkan pada kelompok kontrol sebagian besar responden menyatakan bahwa faktor budaya mendukung penggunaan Alat Kontrasepsi Dalam Rahim. Berbeda dengan penelitian Wulandari (2015) di Puskesmas Merangsan kota Yogyakarta bahwa Dari semua variabel penelitian sosial budaya (umur, pendidikan, pekerjaan, agama, kepercayaan) tidak ada berhubungan yang signifikan dengan keikutsertaan KB IUD.

Sosial budaya adalah sistem gagasan, tindakan dan hasil karya manusia dalam kehidupan masyarakat yang dilahirkan dari diri manusia melalui proses pembelajaran (Koentjaraningrat, 2014). Sosial budaya adalah segala hal yang dicipta oleh manusia dengan pemikiran dan budi nuraninya untuk dan atau dalam kehidupan bermasyarakat. Atau lebih singkatnya manusia

Nopita Yanti Sitorus", R. Maimunah

Program Studi D-III Kebidanan STIKes Flora. *Email: nopistr27@gmail.com 
Keikutsertaan menjadi akseptor KB ditinjau dari aspek sosial budaya dan dukungan keluarga

membuat sesuatu berdasar budi dan pikirannya yang diperuntukkan dalam kehidupan bermasyarakat (Ranjabar, 2016).

Sebagai makhluk sosial manusia hidup tidak terlepas dari budaya bahkan dapat dipengaruhi oleh budaya di mana ia hidup. Budaya menyangkut adat istiadat, tradisi, kebiasaan, aturan-aturan dan pendapat-pendapat. Penggunaan alat kontrasepsi juga turut dipengaruhi oleh faktor sosial budaya masyarakat mengingat penggunanya hidup dalam lingkungan budaya masyarakat (Aritonang, 2015). Hasil penelitian ini membuktikan bahwa keikutsertaan ibu berhubungan dengan sosial budaya yang berkembang dalam masyarakat. Masyarakat yang sudah tidak mempercayai mitosmitos yang berkembang di masyarakat cenderung menggunakan alat kontrasepsi dibandingkan mereka yang masih mempercayai mitos.

Kepercayaan yang masih dipercayai oleh sebagian masyarakat yaitu banyak anak banyak rezeki, setiap anak memiliki rezeki masing-masing sehingga jika anaknya banyak maka rezekinya juga akan banyak. Selain itu ada juga masyarakat yang dalih agama bahwa melakukan KB dilarang agama (haram) sehingga mereka tidak menggunakan alat kontrasepsi. Kebiasaan masyarakat yang lebih menghargai anak laki-laki dibandingkan anak perempuan sehingga ketika anaknya sudah ada 2-4 orang tetapi belum memiliki anak laki-laki maka mereka berusaha untuk mendapatkan anak laki-laki, yang berarti istri tidak menggunakan alat kontrasepsi dan harus hamil/melahirkan lagi dengan harapan pada kehamilan ini akan mendapatkan anak laki-laki. Sebagian responden juga beranggapan bahwa dengan anak yang sedikit maka tidak ada yang mengurusnya pada saat tua nanti.

Berdasarkan hasil penelitian menunjukkan bahwa ada hubungan yang signifikan antara dukungan keluarga dengan keikutsertaan $\mathrm{KB}$, $p=0,000<0,05$. Responden yang menyatakan keluarganya mendukung mayoritas ikutserta menggunakan $\mathrm{KB}$, sedangkan responden yang menyatakan keluarganya tidak mendukung mayoritas tidak ikutserta menggunakan KB.

Penelitian ini sejalan dengan penelitian Puspitasari \& Nurunniyah (2016) di Desa Argomulyo Sedayu Bantul Yogyakarta mendapatkan hasil bahwa terdapat hubungan positif antara dukungan keluarga dengan keikutsertaan KB pada Pasangan Usia Subur (PUS). Demikian juga penelitian yang dilakukan oleh Musdalifah (2013) di Wilayah Kerja Puskesmas Lampa, Duampanua, Pinrang yang menyimpulkan bahwa dukungan suami (keluarga) berhubungan positif dengan pemilihan alat kontrasepsi hormonal.

Dukungan keluarga adalah suatu bentuk hubungan interpersonal yang melindungi seseorang dari efek stres yang buruk (Kaplan \& Sadock, 2015). Dukungan sosial keluarga mengacu kepada dukungan-dukungan sosial yang dipandang oleh anggota keluarga sebagai sesuatu yang dapat diakses atau diadakan untuk keluarga yang selalu siap memberikan pertolongan dan bantuan jika diperlukan (Andarmoyo, 2015). Sistem dukungan keluarga ini berupa membantu berorientasi tugas sering kali diberikan oleh keluarga besar, teman, dan tetangga. Bantuan dari keluarga besar juga dilakukan dalam bentuk bantuan langsung, termasuk bantuan financial yang terus-menerus dan intermittent, berbelanja, merawat anak, perawatan fisik lansia, melakukan tugas rumah tangga, dan bantuan praktis selama masa krisis (Friedman, 2015).

Dukungan keluarga yang diterima responden dalam hal ini dukungan yang memberi kontribusi pada keikutsertaan KB berhubungan dengan kualitas dan kuatnya hubungan serta persepsi memiliki orang lain yang dapat dipercaya dan diandalkan untuk memberikan dukungan jika sewaktu-waktu diperlukan. Pendapat lain mengemukakan bahwa ikatan keluarga yang kuat sangat membantu ketika keluarga menghadapi masalah, karena anggota keluarga sangat membutuhkan dukungan dan bantuan dari anggota keluarga yang lain (Puspitasari \& Nurunniyah, 2016).

Hasil penelitian ini membuktikan bahwa dukungan keluarga terutama suami berhubungan erat dengan keikutsertaan ibu dalam penggunaan alat kontrasepsi KB. Ibu yang mendapatkan dukungan cenderung merasa yakin untuk menggunakan alat kontrasepsi dan pada umumnya ibu akan merasa nyaman menggunakan alat kontrasepsi tersebut. Sementara ibu yang tidak mendapatkan dukungan dari keluarga (suami) cenderung tidak menggunakan alat kontrasepsi dengan berbagai alasan seperti permintaan suami agar istri tidak menggunakan alat kontrasepsi karena masih menginginkan memiliki anak lagi, takut efek samping alat kontrasepsi yang digunakan, tidak memberikan 
uang untuk membayar alat kontrasepsi yang akan digunakan ibu sehingga ibu tetap menggunakan alat kontrasepsi tersebut.

lbu yang mendapatkan dukungan dari keluarga (suami) maka akan bersama-sama untuk mencari informasi dan bertanya pada tenaga kesehatan alat kontrasepsi yang cocok untuk ibu, keluarga (suami) menganjurkan pada istri untuk menggunakan alat kontrasepsi yang cocok atau paling kecil efek sampingnya. Suami juga menyediakan uang dan bersedia mengantar istri untuk berkunjung ke fasilitas kesehatan seperti klinik bidan, puskesmas, dan fasilitas kesehatan lainnya yang menyediakan alat kontrasepsi. Selain itu, suami memberikan dukungan emosional seperti menguatkan ibu dengan menghargai pilihan ibu, memberi pujian yang membuat ibu merasa lebih nyaman dalam menggunakan alat kontrasepsi.

\section{SIMPULAN}

Aspek sosial budaya dan dukungan keluarga berhubungan erat dengan keikutsertaan KB , $p=0,000<0,05$. di Wilayah kerja Puskesmas Kota Datar Desa Tandem Hulu I Kecamatan Hamparan Perak Kabupaten Deli Serdang.

\section{SARAN}

Kepada manajemen pelayanan Puskesmas Kota Datar untuk melakukan monitor dan evaluasi terhadap pencapaian keikutsertaan KB terutama di Desa Tandem Hulu I sehingga dapat ditingkatkan keikutsertaan PUS dalam pemakaian alat kontrasepsi KB. Para bidan juga supaya dilibatkan untuk memberikan penyuluhan tentang alat kontrasepsi KB kepada PUS yang belum menggunakan alat kontrasepsi agar memilih dan menggunakan alat kontrasepsi KB yang cocok untuk dirinya sehingga dapat menekan angka pertumbuhan penduduk dan meningkatkan kesejahteraan keluarga.

\section{DAFTAR PUSTAKA}

Andarmoyo, S. (2015). Keperawatan Keluarga Konsep Teori, proses DanPraktik Keperawatan (Cetakan 2). Yogyakarta: Graha IImu.

Aritonang, J. (2015). Hubungan Budaya Patriarki terhadap Keputusan WUS Menjadi Akseptor Keluarga Berencana di Lingkungan VI Simpang Selayang Medan Tuntungan Tahun 2010,.
Program D-IV Bidan Pendidik Universitas Sumatera Utara.

Assalis, H. (2015). Hubungan sosial budaya dengan pemilihan metode kontrasepsi. Jurnal Kesehatan, VI(2), 142-147.

Badan Pusat Statistik. (2015). Profil Kesehatan Ibu dan Anak. Jakarta: BPS.

Badan Pusat Statistik. (2016). Indikator Kesejahteraan Rakyat. Jakarta: BPS.

BKKBN. (2016). Keluarga Berencana dan Kesehatan Reproduksi (Cetakan 2). Jakarta: Badan Kependudukan dan Keluarga Berencana Nasional (BKKBN).

BKKBN. (2017). Keluarga Berencana dan Kontrasepsi. Jakarta: Badan Kependudukan dan Keluarga Berencana Nasional (BKKBN).

BKKBN. (2018). Panduan Promosi dan Konseling Kesehatan Reproduksi dalamProgram Kependudukan, Keluarga Berencana dan Pembangunan Keluarga. Jakarta: Badan Kependudukan dan Keluarga Berencana Nasional (BKKBN).

BKKBN. (2019). Laporan Badan Kependudukan dan Keluarga Berencana Nasional Tahun 20152019. Jakarta: Badan Kependudukan dan Keluarga Berencana Nasional (BKKBN).

BPS. (2018). Proyeksi Jumlah Penduduk 2020 Menurut Provinsi (SUPAS 2015). Jakarta: Badan Pusat Statistik (BPS).

Darmawati, D., \& Rakhmah, A. N. (2017). Keikutsertaan menjadi akseptor keluarga berencana pada pasangan usia subur ditinjau dari aspek sosial dan budaya. Idea Nursing Journal, 8(1), 58-62.

Friedman, M. (2015). Buku Ajar Keperawatan Keluarga Riset, Teori dan Praktik (Edisi ke-7). Jakarta: Penerbit Buku Kedokteran EGC.

Hartanto, H. (2017). Keluarga Berencana dan Kontrasepsi (Cetakan 4). Jakarta: Pustaka Sinar Harapan. 
Keikutsertaan menjadi akseptor KB ditinjau dari aspek sosial budaya dan dukungan keluarga

Kaplan, H. I., Sadock, B. J., \& Grebb, J. A. (1994). Kaplan and Sadock's synopsis of psychiatry: Behavioral sciences, clinical psychiatry. Williams \& Wilkins Co.

Koentjaraningrat, K. (2014). Pengantar IImu Antropologi (Cetakan 4). Jakarta: Rineka Cipta.

Manuaba, I. G. B. (2014). Ilmu Kebidanan Penyakit Kandungan dan Keluarga Berencana. Jakarta: Penerbit Buku Kedokteran EGC.

Manuaba, I. G. B. (2016). Memahami Kesehatan Reproduksi Wanita (Cetakan 6). Jakarta: Penerbit Buku Kedokteran EGC.

Musdalifah, S. M. \& Rahma, R. (2014). Faktor yang Berhubungan Dengan Pemilihan Kontrasepsi Hormonal Pasutri di Wilayah Kerja Puskesmas Lampa Kecamatan Duampanua Kabupaten Pinrang 2013. Naskah IImiah.

Noorkasiani, M. K., Heryati, S. K., \& Ismail, R. S. K. (2016). Sosiologi keperawatan. EGC.

Puspitasari, D., \& Nurunniyah, S. (2016). Dukungan Keluarga dalam Keikutsertaan KB pada Pasangan Usia Subur di Desa Argomulyo Sedayu Bantul Yogyakarta. Jurnal Ners Dan Kebidanan Indonesia, 2(3), 93-98.

Ranjabar, J. (2016). Sistem Sosial Budaya Indonesia: Suatu Pengantar (Edisi 3). Bogor: Ghalia Indonesia.
Sarafino, E. P. (2014). Health Psychology: Biopsychosocial Interactions. USA: John Wiley \& Sons.

Setiadi, E. M. (2017). Ilmu Sosial dan Budaya Dasar (Cetakan 3). Jakarta: Kencana Prenanda Media Group.

Setiowati, T. (2018). Faktor-faktor Yang Berhubungan Dengan Penggunaan Alat Kontrasepsi Dalam Rahim Pada Akseptor KB Golongan Risiko Tinggi di Puskesmas Wilayah Kecamatan Cimahi Selatan Kota Cimahi. Skripsi.

Suratun, S., Tien, H., \& Rusmiati, S. (2017). Pelayanan Keluarga Verencana dan Pelayanan Kontrasepsi. Jakarta: Trans Info Media.

Wiknjosastro, H. (2015). Ilmu Kebidanan (Cetakan 8). Jakarta: Yayasan Bina Pustaka Sarwono Prawirohardjo.

Wulandari, S. (2015). Hubungan Faktor Sosial Budaya dengan Keikutsertaan KB IUD di Puskesmas Merangsan kota Yogyakarta Tahun 2013. Jurnal Medika Respati, 10(1), 19073887. 